\title{
Erratum to: Molecular epidemiology and phylogenetic analysis of Hepatitis B virus in a group of migrants in Italy
}

Umbertina Villano ${ }^{1 \dagger}$, Alessandra Lo Presti ${ }^{2+}$, Michele Equestre ${ }^{3}$, Eleonora Cella ${ }^{2}$, Giulio Pisani ${ }^{4}$, Marta Giovanetti ${ }^{2}$, Roberto Bruni ${ }^{1}$, Elena Tritarelli ${ }^{1}$, Massimo Amicosante ${ }^{5}$, Alba Grifoni ${ }^{6}$, Carmelo Scarcella ${ }^{7}$, Issa El-Hamad ${ }^{7,8}$, Maria Chiara Pezzoli ${ }^{7}$, Silvia Angeletti ${ }^{9}$, Anna Rita Ciccaglione ${ }^{1}$ and Massimo Ciccozzi ${ }^{2, *^{*}}$

After publication of the original article [1] it came to the authors' attention that Silvia Angeletti's name was displayed incorrectly as 'Angeletti Silvia'. The correct spelling of Silvia Angeletti's name has been updated in the original article and is corrected with this erratum.

\begin{abstract}
Author details
${ }^{1}$ Viral Hepatitis Unit, Department of Infectious, Parasitic and

Immune-Mediated Diseases, Istituto Superiore di Sanità, Rome, Italy

2Epidemiology Unit, Department of Infectious, Parasitic and

Immune-Mediated Diseases, Istituto Superiore di Sanità, Rome, Italy.

${ }^{3}$ Department of Cell Biology and Neurosciences, Istituto Superiore di Sanità,

Rome, Italy. ${ }^{4}$ Center for Immunobiologicals Research and Evaluation, Istituto

Superiore di Sanità, Rome, Italy. ${ }^{5}$ Department of Biomedicine and Prevention,

University of Rome "Tor Vergata", Rome, Italy. 'Department of Biology,

University of Rome "Tor Vergata", Rome, Italy. "Department of Infectious

Diseases, Spedali Civili General Hospital, Brescia, Italy. ${ }^{8}$ Brescia Local Health

Authority, Brescia, Italy. ${ }^{9}$ Clinical Pathology and Microbiology Laboratory,

University hospital Campus Biomedico, Rome, Italy.
\end{abstract}

Received: 3 August 2015 Accepted: 28 September 2015

Published online: 17 November 2015

\section{Reference}

1. Villano U, Presti AL, Equestre M, Cella E, Pisani G, Giovanetti M, et al.

Molecular epidemiology and phylogenetic analysis of Hepatitis B virus in a

group of migrants in Italy. BMC Infect Dis. 2015;15:287.

\footnotetext{
* Correspondence: massimo.ciccozzi@iss.it

${ }^{\dagger}$ Equal contributors

2Epidemiology Unit, Department of Infectious, Parasitic and

Immune-Mediated Diseases, Istituto Superiore di Sanità, Rome, Italy

${ }^{9}$ Clinical Pathology and Microbiology Laboratory, University hospital Campus

Biomedico, Rome, Italy
}

\section{Submit your next manuscript to BioMed Central and take full advantage of:}

- Convenient online submission

- Thorough peer review

- No space constraints or color figure charges

- Immediate publication on acceptance

- Inclusion in PubMed, CAS, Scopus and Google Scholar

- Research which is freely available for redistribution 